\title{
Violencia y culturas juveniles masculinas en la sociedad rural de principios del siglo XX: la Tierra de Campos*
}

\author{
Jesús-Ángel REDONDO CARDEÑOSO \\ Instituto Universitario de Historia Simancas (Universidad de Valladolid) \\ jredondocardenoso@gmail.com
}

Recibido: 06/09/2010

Aceptado: 24/02/2011

\section{RESUMEN}

En el siguiente texto analizamos las diversas manifestaciones violentas que ejecutaron los mozos campesinos españoles de los inicios del siglo XX, principalmente mediante el estudio de Sentencias Criminales y tomando como ejemplo a la comarca castellano-leonesa de Tierra de Campos. En esta comarca, a igual que sucedía con buena parte de la España rural de la época, las estadísticas muestran que los jóvenes eran los ejecutores de la mayor parte de los actos violentos. Sin embargo, a través de un análisis cualitativo de caso, podemos ver cómo dicho corpus violento tenía poco que ver con motivaciones políticas y conflictos socio-económicos de clase. Muy al contrario, esta violencia juvenil estuvo motivada por cuestiones culturales y conceptos mentales enmarcados en las relaciones sociales de la vida cotidiana, entre las que destacó la defensa de valores como el honor -tanto colectivo como individual-, y en especial su variante masculina, la hombría.

Palabras clave: violencia, juventud, sociedad rural, honor, armas.

Violence and Youth Male Cultures in the Rural Rociety at the Beginning of the $20^{\text {th }}$ Century: the Tierra de Campos

\begin{abstract}
In the next text, we analyze several violent expressions which were carried out by the rural young people at the beginning of the $20^{\text {th }}$ century, mainly through the study of Criminal Judgments and taking the example of Tierra de Campos, a rural region in Castile and León (Spain). Here, as was the case for the majority of rural Spain at these years, the statistics show us that young people were the perpetrators of most of violent actions. However, we can see through a qualitative analysis how that violence was not related with politically motivations and socio-economic conflicts. On the contrary, this youth violence was motivated by cultural issues and mental concepts framed in the social relationships of everyday life, as the defence of values like honour -both collective and individual-, and especially its male variant, the manliness.
\end{abstract}

Key words: violence, young people, rural society, honour, weapons.

Sumario: Introducción. 1.Violencia juvenil colectiva: los bandos de mozos. 1.a. Los enfrentamientos juveniles intercomunitarios. 1.b. Los enfrentamientos juveniles intracomunitarios. 2.Violencia interpersonal de los mozos: la defensa de la virilidad a través de la fuerza. 3. Las armas: una cosa de "hombres", 4. Conclusión.

\footnotetext{
${ }^{*}$ Una versión previa a este trabajo fue presentada al II Encuentro de Jóvenes Investigadores en Historia Contemporánea de la AHC celebrado en la Universidad de Granada en septiembre de 2009, bajo el título «Violencia, mocedad y sociedad rural: la Tierra de Campos palentina entre 1900-1923». Ambas aportaciones se han realizado gracias a la Beca de Formación de Personal Investigador (Orden EDU/918/2006 de 30 de mayo) de la Consejería de Educación de la Junta de Castilla y León, cofinanciada por el Fondo Social Europeo.
} 
"Discutiendo están dos mozos/ si a la fiesta del lugar irán por la carretera/ o campo traviesa irán.

Discutiendo y disputando/ empiezan a pelear. Ya con las trancas de pino/ furiosos golpes se dan; ya se tiran de las barbas/ ya se las quieren pelar.

\section{Introducción}

La juventud o, utilizando una terminología tradicional, mocedad, es la fase vital del individuo que comienza cuando éste adquiere la madurez sexual hasta que crea un nuevo núcleo familiar mediante el matrimonio. A pesar de la aparente claridad de estos límites cronológicos, el acceso a la mocedad mantuvo un carácter difuso durante largo tiempo ${ }^{1}$. Dentro de la comunidad rural, las primeras muestras de que el niño ya se estaba convirtiendo en hombre se daban en torno a los 13-14 años, y se mostraban en pequeños aspectos de la vida cotidiana como la indumentaria, cuando se comenzaba a vestir al chiquillo como a un hombrecito en las fiestas ${ }^{2}$, o el trabajo, dedicándose a tiempo completo a las labores agrícolas ${ }^{3}$. Así, por ejemplo, en el caso de la recolección, los jóvenes dejaban de realizar las labores de mochil $^{4}$ y comenzaban a ejecutar tareas propias de adultos como segar, trillar y beldar. Todas estas manifestaciones se complementaban con los cambios orgánicos propios de la edad, como era la aparición de la barba o el cambio de voz. A estos síntomas cotidianos, en el siglo XIX se añadió una nueva delimitación de la juventud por parte del Estado cuando se implantó el servicio militar obligatorio. Este hecho tuvo mucho más significado que el simple llamamiento a quintas, ya que permitió fortalecer en los jóvenes "el sentimiento de

${ }^{1}$ Las abreviaturas utilizadas en el texto son: ARChV, Archivo de la Real Chancillería de Valladolid; AHPP, Archivo Histórico Provincial de Palencia; y AHPZ, Archivo Histórico Provincial de Zamora. La concepción que actualmente tenemos de juventud se desarrolló en Europa entre finales del siglo XVIII y principios del XIX; SOUTO KUSTRÍN, Sandra, "Introducción: juventud e historia", Hispania, 225 (2007), p. 12.

${ }^{2}$ FABRE, Daniel, “"Forjar la juventud' en el pueblo”, en LEVI, Giovanni y SCHMITT, Jean Claude (dirs.), Historia de los jóvenes. II. La Edad contemporánea, Madrid, Taurus, 1996, p. 76.

${ }^{3}$ BORRÁS LLOP, José María, "El trabajo infantil en el mundo rural español, 1849-1936", en MARTÍNEZ CARRIÓN, José Miguel (coord.), El nivel de vida en la España rural, siglos XVIII-XX, Alicante, Universidad de Alicante, 2002, p. 511.

${ }^{4} \mathrm{El}$ mochil era "un joven que ayudaba a recoger gavillas y, sobre todo, que procuraba mantener la bebida fresca, llevaba la comida a los segadores y buscaba una sombra para comer"; GONZÁLEZ TORICES, José y DÍEZ BARRIO, Germán, Aperos de madera, Valladolid, Junta de Castilla y León, 1991, p. 67. 
pertenecer a un concreto grupo en el que todos tenían la misma edad"s, creando una identidad comunitaria.

La juventud, que a partir de este momento estableceremos de forma genérica entre los 16 y 25 años, tenía un papel especial dentro de la vida de la comunidad rural local, principalmente porque constituía un orden social alternativo al mundo de los adultos que tenía propios gobernantes ${ }^{6}$, fiestas, costumbres y exclusivos espacios de sociabilidad.

A través de esta particular sociabilidad, los mozos accedían a "un laboratorio de saber práctico en el que cabía experimentar con la adquisición de las normas imperantes" ". Los rituales, costumbres y acciones que protagonizaban se constituían en una forma de autoeducación colectiva para el acceso a la edad adulta, donde se establecía "una dialéctica del acatamiento de reglas y de la violación admitida de las mismas" . En este contexto, los mozos debían de demostrar constantemente pruebas de su valor ante la opinión pública local para así justificar que serían dignos miembros de pleno derecho de la comunidad que integraban'. Este hecho queda reflejado en multitud de actos públicos. Por ejemplo, no era raro ver cómo se juzgaba la capacidad física de los jóvenes terracampinos en los partidos de pelota celebrados en los frontones de los pueblos, juego que fue el deporte más popular de la comarca durante la época estudiada ${ }^{10}$.

También se juzgaba la pericia de los mozos en otros rituales relacionados con la violencia ejercida contra los animales. Ejemplos son las carreras de gallos, en las cuales los quintos, a lomos de un caballo a galope, intentaban decapitar un gallo colgado de una cuerda ${ }^{11}$; o las capeas y corridas de toros rurales:

"Y hay que haber visto un pueblo entero, borracho de vino y de barbarie, acosando a un pobre animal indefenso; hiriéndole con rejones; golpeándole con varas, y atormentándole de mil maneras hasta que los mansos le retiran al corral hecho una llaga

${ }^{5}$ LORIGA, Sabina, "La experiencia militar", en LEVI, Giovanni y SCHMITT, Jean Claude (dirs.), Historia de los jóvenes. II... op. cit., p. 36.

${ }^{6}$ En Sahagún, en la Tierra de Campos leonesa, existía el "rey de mozos" (CARO BAROJA, Julio, El carnaval (análisis histórico-cultural), Madrid, Taurus, 1986, p. 339); y en la Francia del Antiguo Régimen el “ 'magistrado', 'capitán' o 'abad de la juventud' " (BAUBÉROT, Arnaud, "Los movimientos juveniles en la Francia de entreguerras", Hispania, 225 (2007), p. 22).

${ }^{7}$ SCHINDLER, Norbert, "Los guardianes del desorden. Rituales de la cultura juvenil en los albores de la era moderna", en LEVI, Giovanni y SCHMITT, Jean Claude (dirs.), Historia de los jóvenes. I. De la Antigüedad a la Edad Moderna, Madrid, Taurus, 1996, pp. 308-309.

${ }^{8}$ Ibid.

${ }^{9}$ DI BELLA, Maria Pia, "El nombre, la sangre y los milagros: derecho al renombre en la Sicilia tradicional", en PITT-RIVERS, Julian y PERISTIANY, John G. (eds.), Honor y gracia, Madrid, Alianza, 1993, pp. 204-205.

${ }^{10}$ GARCÍA ABAD, P. Albano, "Gentes, costumbres, folklore, lenguaje y otros aspectos de Tierra de Campos", Publicaciones de la Institución Tello Téllez de Meneses, 59 (1988), p. 770.

11 DEL ARCO MARTÍN, Eduardo; GONZÁLEZ CASSARRUBIOS, Consolación; PADILLA MONTOYA, Carmen y TIMÓN TIEMBLO, María Pía, España: fiesta y rito. Tomo 1, Fiestas de invierno, Madrid, Ediciones Merino, 1994, pp. 332-333. 
o exhala el último aliento a la vista de un millar de espectadores que presencian su muerte con alegría de caníbales"12

Estas exhibiciones públicas tenían suma importancia en las relaciones juveniles de la sociedad rural e incluso, en el caso de las capeas, se convertían en festejos indispensables en las fiestas patronales, de tal modo que su no celebración podía originar importantes conflictos. Tal es el caso de los sucesos que tuvieron lugar en Villafáfila, en el año 1900, cuando por orden del alcalde se celebró el encierro de las fiestas patronales la noche del 15 de agosto, "para evitar desgracias", en vez de la mañana del 16 como era la costumbre. Ante tal cambio, una multitud de vecinos fueron a los corrales en busca del ganado "con objeto de sacarlo de él y volver a encerrarlo por la mañana", produciéndose un tumulto en el que tuvo que intervenir la Guardia Civil y donde resultó agredido un concejal. El alboroto se repitió de madrugada cuando "volvieron a presentarse en el corral del ganado otros muchos individuos y lograron abrir la puerta, y echarlo afuera como pretendieron hacerlo por la noche"13. Del mismo modo, en Villarramiel, en agosto de 1920, tras quedar desierta la subasta de las vaquillas que se debían de lidiar en las fiestas patronales, "parte del vecindario se amotinó, intentando agredir al alcalde" 14 .

Pero el constante examen de capacidad al que estaban expuestos los mozos de las sociedades rurales no sólo se manifestaba a través de juegos ritualizados como los señalados, sino que también se ejecutaban mediante una violencia física ejercida contra las personas que, no pocas veces, terminaba con sangrientas consecuencias, como ocurría en las fiestas ${ }^{15}$.

Es esclarecedor ver cómo las estadísticas judiciales de la Restauración muestran que la mayoría de los procesados por delitos contra las personas eran jóvenes ${ }^{16}$. Para profundizar en el papel que tuvo la juventud española en el ejercicio

${ }^{12}$ SENADOR GÓMEZ, Julio, Castilla en escombros: las leyes, las tierras, el trigo y el hambre, Valladolid, Ámbito, 1993 ( $1^{\text {a }}$ ed. 1915), p. 276; a pesar de la posible aparente exageración de las palabras de Julio Senador, si leemos otro tipo de documentación, como es un bando municipal promulgado por el Ayuntamiento de Paredes de Nava en 1927, vemos que las palabras del primero no debían de alejarse mucho de la realidad: «... queda prohibida la estancia en el redondel de toda persona menor de 18 años y mayor de 60, así como de cuantos no se hallen en perfecto estado de lucidez. También se prohíben las varas con picas y rejas, arrojar piedras, varas o artefactos a las vacas; y colgar al interior de la plaza tablones ni aparatos de ninguna clase»; recogido en ALONSO GARCÍA, David, Paredes de Nava. Imágenes del ayer, Palencia, Ayuntamiento de Paredes de Nava, 2005, p. 114.

${ }^{13}$ Heraldo de Zamora, 20 de agosto de 1900 y AHPZ, Sentencias criminales, año 1902, $\mathrm{n}^{\circ} 135$.

${ }^{14}$ El Día de Palencia, 18 de agosto de 1920.

15 “..., los rituales de iniciación (de los varones, claro) están muy presentes en las fiestas españolas [...]. Y conceptos como el valor, la pertenencia al grupo y, con demasiada frecuencia, la violencia siguen estando muy presentes", en SÁNCHEZ GÓMEZ, María Ángeles, "Las fiestas, escuela de la vida", en ALONSO PONGA, José Luis et alii, Las fiestas. De la antropología a la historia y la etnografía, Salamancas, Centro de Cultura Tradicional, 1999, p. 109.

${ }^{16}$ Así, por ejemplo, el 55\% de los procesados en 1916 por ese tipo de delitos tenían entre 15 y 25 años; I.N.E., Administración de justicia en lo criminal, Clasificación de los procesados, por títulos del Código Penal, y conclusiones individuales de aquéllos. Año 1916. 
de la violencia del primer siglo XX hemos realizado un estudio de una comarca castellano-leonesa, la Tierra de Campos ${ }^{17}$.

Localización de la comarca de estudio

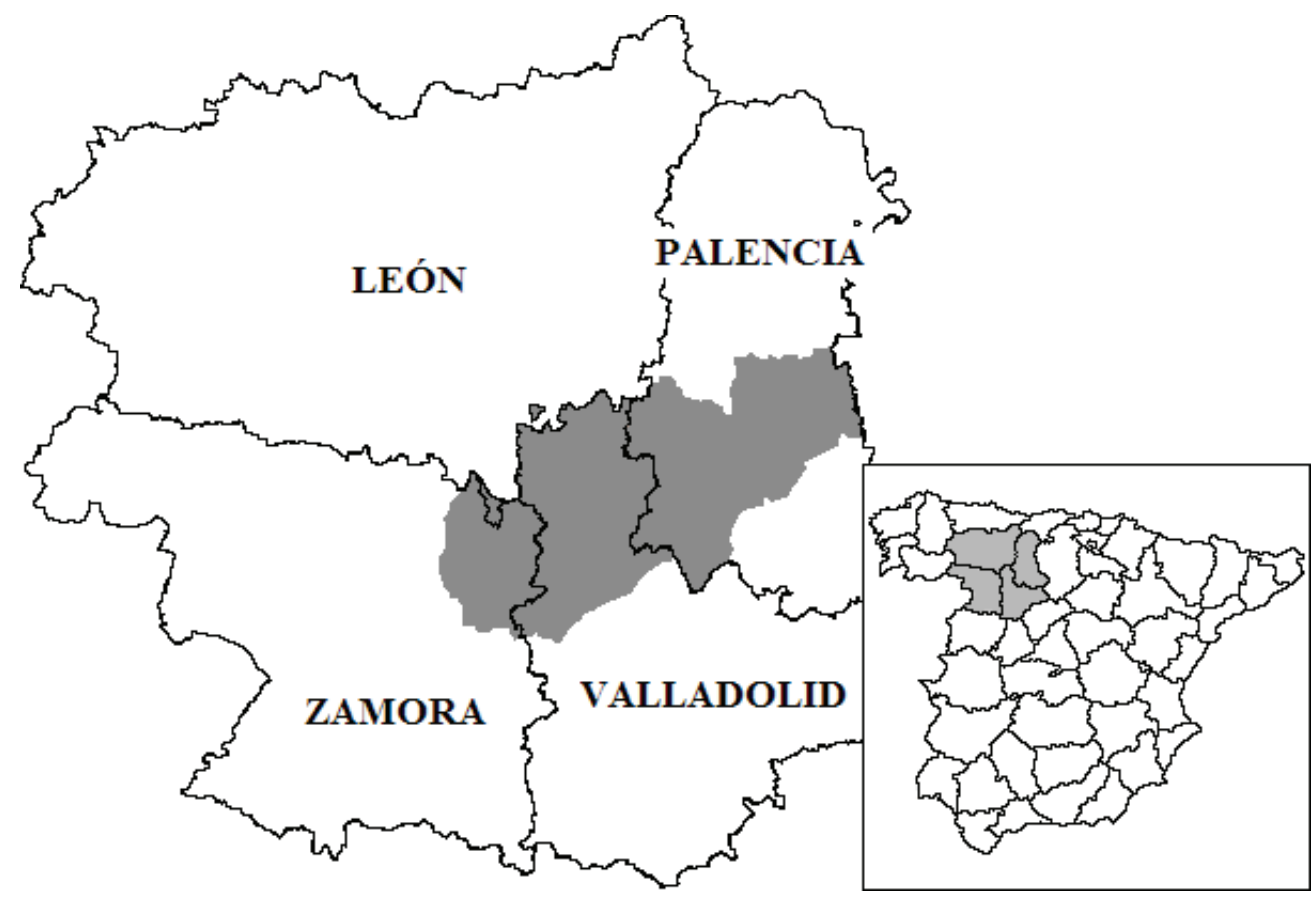

FUENTE: Elaboración propia.

Nos hemos centrado, por tanto, en una región eminentemente rural ${ }^{18}$, dejando al margen la sociedad urbana, ya que entendemos que ambos ámbitos tuvieron un desarrollo socio-cultural radicalmente distinto ${ }^{19}$. Además, el hecho de que la mayoría de los habitantes de la España de principios del siglo XX vivieran en ámbitos rurales nos acerca más una realidad generalizada en la época.

Para realizar esta investigación hemos analizado los actos violentos producidos entre los años 1900 y 1923 que han quedado reflejados en los Libros de Sentencias Criminales custodiados en el Archivo de la Real Chancillería de Valladolid, Archi-

\footnotetext{
${ }^{17}$ La región estudiada incluye 166 municipios enclavados en las provincias de Palencia, Valladolid y Zamora que tenían en 1900 y 1920 una población de hecho de 145.236 y 132.420 habitantes, respectivamente (I.N.E., Censos de población de 1900 y 1920).

${ }^{18}$ Los municipios con mayor población eran Medina de Rioseco (Valladolid) con 5.007 y 4.791 habitantes en los mismos años 1900 y 1920; y Paredes de Nava (Palencia) con 4.676 y 4.613 habitantes.

${ }^{19}$ Véase THUILLIER, Guy, Pour une histoire du quotidien au XIX siècle en Nivernais, París/La Haye, Mouton, 1977.
} 
vo Histórico Provincial de Palencia y Archivo Histórico Provincial de Zamora ${ }^{20}$, las cuales muestran que también los jóvenes terracampinos eran los principales protagonistas de la mayoría de actos violentos. Además hemos complementado dicha información con la que ofrecen las páginas de los periódicos de las mismas provincias El Norte de Castilla, Diario Regional, Heraldo de Zamora, El Diario Palentino y El Día de Palencia.

\section{Edad de los procesados por actos violentos en la Tierra de Campos, 1900-1923}

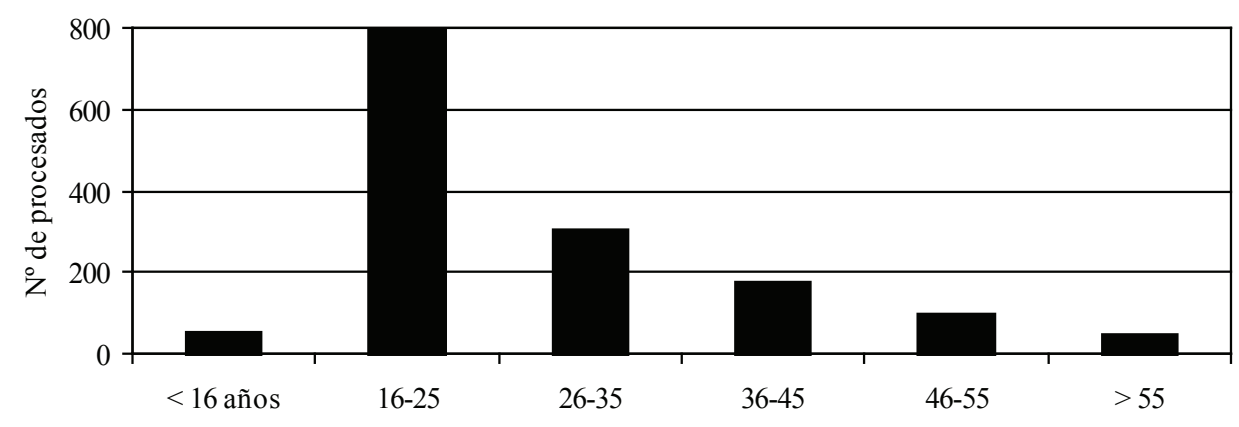

FUENTE: ARChV, AHPP y AHPZ,

Sentencias criminales, años 1900-1924. Elaboración propia.

Ahora bien, debemos de tener en cuenta los límites que presenta la documentación judicial, cuyo origen no fue comprender la violencia en las mentalidades de las clases populares de la época, sino simplemente repartir responsabilidades delictivas para establecer culpabilidades y penas jurídicas a los procesados. Por ello, para conocer mejor las manifestaciones violentas que protagonizaron los jóvenes terracampinos debemos de dejar a un lado las estadísticas y atender a las causas y motivaciones que propiciaron este fenómeno, acercarnos al individuo y sumergirnos en la sociedad rural a través de la lectura de la documentación ${ }^{21}$.

\footnotetext{
${ }^{20}$ En este sentido, si por un lado sí que hemos podido acceder a las series completas de los Libros de Sentencias criminales dictadas en los juicios de derecho, no sucede lo mismo con las derivadas de los juicios de jurado, faltando los correspondientes a los años 1909, 1916, 1917, 1918 y 1919 de la Audiencia de Valladolid y los de los años 1901, 1909, 1910 y 1911 de la Audiencia de Zamora.

${ }^{21}$ En este sentido hemos tenido lo mismos problemas que en su día señaló M. Baumeister, quien tras llevar a cabo un primer acercamiento a las caóticas estadísticas judiciales de la Restauración, termina por rendirse y señalar que a la hora de estudiar la violencia cotidiana del campesinado "merece más la pena analizar la situación en el ámbito micro, con casos, en vez de construir un modelo de variables lo más cerrado posible"; en BAUMEISTER, Martin, Campesinos sin tierra. Supervivencia y resistencia en Extremadura, 1880-1923, Badajoz, Diputación de Badajoz, 1996, p. 158.
} 
Para ello hemos estructurado el trabajo en tres partes. Primero afrontaremos el estudio de la violencia ejercida por los jóvenes terracampinos de forma colectiva, tanto los conflictos originados entre comunidades vecinas como los conflictos originados en el seno del propio vecindario. En un segundo punto nos centraremos en la violencia juvenil ejercida de forma individual, donde los mozos defendían a la familia o su propio honor y respetabilidad. Para terminar analizaremos la presencia de las armas - principalmente las de fuego- en el utillaje cultural de los jóvenes de la comarca, lo cual es un buen método para percibir la importancia que alcanzaba en las relaciones sociales de aquellos individuos tanto la violencia como el estar bien equipado para ejercerla.

\section{Los enfrentamientos juveniles intercomunitarios ${ }^{22}$}

\section{1a. Los enfrentamientos juveniles intercomunitarios}

La expresión de violencia juvenil que más éxito ha tenido en la historiografía ha sido las riñas entre grupos de mozos de pueblos vecinos. C. Tilly señaló a éstas como una de las expresiones de violencia colectiva más característica del Antiguo Régimen, las cuales fueron desapareciendo del repertorio de violencia colectiva de la sociedad francesa desde la segunda mitad del siglo XIX ${ }^{23}$. Sin embargo, en el caso de nuestro país, y a diferencia de otros países europeos, la violencia interpersonal propia de sociedades preindustriales todavía se extendía en dicha centuria por todo el cuerpo social ${ }^{24}$, hecho que se puede aplicar perfectamente al primer cuarto del $\mathrm{XX}^{25}$. En este sentido, los mozos campesinos españoles de esta época seguían siendo, a igual que ocurría en época moderna, "el "fer de lance" del patriotismo de la aldea"26, asumiendo roles propios de sociedades preindustriales como era garantir el honor de la comunidad local, cuya mejor expresión era la masculinidad de los propios mozos manifestada a través del ejercicio de la violencia en comunidades ajenas ${ }^{27}$.

\footnotetext{
${ }^{22}$ Hasta hoy la historiografía española ha atendido a la acción colectiva de la juventud exclusivamente desde el punto de vista de su participación política, sin entrar en las relaciones sociales enmarcadas en la sociabilidad informal cotidiana: GÓMEZ MOLLEDA, María Dolores (coord.), "Movimientos juveniles en la España contemporánea", Studia Historica. Historia Contemporánea, 5 (1987); GONZÁLEZ CALLEJA, Eduardo (coord.): "Juventud y política en la España contemporánea", Ayer, 59 (2005); y SOUTO KUSTRÍN, Sandra (coord.), "Ser joven en la Europa de entreguerras: política, cultura y movilización", Hispania, 225 (2007).

${ }^{23}$ TILLY, Charles; TILLY, Louise y TILLY, Richard, El siglo rebelde. 1830-1930, Zaragoza, Prensas Universitarias de Zaragoza, 1997, pp. 288-290.

${ }^{24}$ TRINIDAD FERNÁNDEZ, Pedro, La defensa de la sociedad: cárcel y delincuencia en España (ss. XVIII-XX), Madrid, Alianza, 1991, p. 219.

${ }^{25}$ Véase REDONDO CARDEÑOSO, Jesús-Ángel, "Violencia y sociedad rural. La Tierra de Campos palentina (1917-1923)", Historia Agraria, 51 (2010), pp. 81-108.

${ }^{26}$ SAAVEDRA, Pegerto, La vida cotidiana en la Galicia del Antiguo Régimen, Barcelona, Crítica, 1994, p. 204.

${ }^{27}$ VAQUINHAS, Irene, "Alguns aspectos da violencia nos campos portugueses do século XIX", Revista de História da Sociedade e da Cultura, 1 (2001), p. 300.
} 
Así, por ejemplo, grupos de mozos de un pueblo hacían gala de su valía haciéndose dueños de las calles de pueblos vecinos, como sucedió en Revilla de Campos, donde el alcalde denunció a varios mozos del vecino Baquerín de Campos "por haber alterado la tranquilidad en dicho Revilla, recorriendo el pueblo cantando coplas contrarias a la moral y buenas costumbres" ${ }^{28}$. Del mismo modo, diecisiete mozos de Carrión de los Condes sembraron el terror en Villalcázar de Sirga, siendo condenados por varios delitos de lesiones al agredir con palos a diversos vecinos de este último pueblo ${ }^{29}$. En otros casos los enfrentamientos entre grupos de mozos de pueblos vecinos se producían en una tercera localidad, como muestran los hechos que tuvieron lugar en Villarramiel donde se enfrentaron mozos de Paredes de Nava y de Capillas ${ }^{30}$; o en la fiesta patronal de Mazariegos, en la que mozos de Frechilla, Villalumbroso y Guaza de Campos protagonizaron una reyerta de la que resultó un herido por disparo de arma de fuego $0^{31}$.

Pero, no siendo escasas, estas razzias invasoras no eran la muestra más común de enfrentamientos entre grupos de mozos originarios de pueblos vecinos. Las reyertas de este tipo eran principalmente originadas por locales que imponían sus costumbres y normas a jóvenes visitantes, los cuales eran considerados rivales al ocupar éstos un espacio y un protagonismo que los primeros creían que les pertenecía en exclusiva, sobre todo a la hora de participar en los bailes, espacio privilegiado del cortejo juvenil $^{32}$. En este sentido, en un baile de Villelga sostuvieron una reyerta mozos de este pueblo y del vecino Villemar en la que los contendientes iban armados con navajas y palos ${ }^{33}$; y, en las fiestas de Villaherreros, los mozos de Villadiezma, que ya habían asistido a los toros y a merendar a casa del organista, fueron agredidos por los nativos en el baile cuando aquéllos comenzaron a cantar, resultando de la refriega un herido por un navajazo ${ }^{34}$.

La ocasión del enfrentamientos de grupos de mozos de pueblos vecinos también se dio, aunque más excepcionalmente, en tabernas. Baste como muestra la reyerta que protagonizaron mozos de Castrogonzalo y San Esteban del Molar en una taberna de este último pueblo. En medio de una discusión "por rivalidades existentes entre unos y otros", uno de los implicados "apagó la luz, oyéndose inmediatamente un tiro". El tiroteo prosiguió en la calle, donde además se produjeron otros varios encon-

${ }^{28}$ El Diario Palentino, 17 de marzo de 1908.

${ }^{29}$ AHPP, Sentencias criminales, año 1906, nº 203.

${ }^{30}$ El Día de Palencia, 14 de mayo de 1901.

${ }^{31}$ El Diario Palentino, 5 de junio de 1908.

${ }^{32}$ Como ha señalado J. Pitt-Rivers para el caso de un pueblo gaditano durante el franquismo: "Jóvenes que vienen de ciudades vecinas a cortejar a alguna muchacha son tradicionalmente tratados con hostilidad, cuando no con verdadera violencia, por los jóvenes del 'pueblo', cuyo honor colectivo resulta desafiado por su presencia"; PITT-RIVERS, Julian, "Honor y categoría social", en PERISTIANY, John G. (ed.), El concepto del honor en la sociedad mediterránea, Barcelona, Labor, 1968, p. 56.

${ }^{33}$ AHPP, Sentencias criminales, año $1905, \mathrm{n}^{\circ} 80$.

${ }^{34}$ AHPP, Sentencias criminales, año 1914, nº 84. 
tronazos que originaron enfrentamientos cuerpo a cuerpo con armas blancas y de los que resultaron dos heridos de notable gravedad ${ }^{35}$.

\section{1.b. Los enfrentamientos juveniles intracomunitarios}

La violencia que Tilly denominó "primitiva" y "preindustrial" siguió estando plenamente presente en la sociedad rural española del primer tercio del siglo XX; y no sólo a través de enfrentamientos entre mozos de distintos pueblos, como acabamos de ver, sino también, y de manera más patente, entre mozos de un mismo pueblo.

La violencia interpersonal en la España rural de la Restauración era esencialmente ejercida entre las clases populares como un elemento de resolución de conflictos locales entre iguales ${ }^{36}$. No es raro ver, por tanto, que los conflictos violentos protagonizados por grupos de jóvenes se produjeran principalmente en el seno de la comunidad local, y no entre grupos de distintas comunidades, ya que buena parte de las disputas eran originadas por la defensa del honor ${ }^{37}$, y éste se poseía en el lugar de origen ${ }^{38}$.

En concreto, vamos a señalar las tres manifestaciones más comunes de violencia colectiva juvenil intracomunitaria que hemos hallado en la documentación manejada: riñas entre bandos de mozos, rondas nocturnas y cencerradas.

Respecto al primer caso, era habitual que los jóvenes de un pueblo se dividieran en bandos entre los que se producían continuos altercados. Un origen de estas reyertas era, a igual que hemos señalado en el punto anterior, el control de los bailes. En Villacid de Campos se celebró un baile público la tarde del 1 de junio de 1905, donde surgió "una cuestión entre dos bandos contrarios de mozos del pueblo sobre el sitio donde el baile habría de tener lugar", el cual originó una tumultuaria reyerta en la que ambos grupos se enfrentaron con cachavas y palos ${ }^{39}$. Consecuencias más trágicas tuvo la reyerta ocurrida en Osornillo, originada porque los miembros de un bando de mozos no dejaron entrar al baile a sus rivales y en la que un joven resultó herido de muerte por un disparo con arma corta de fuego $0^{40}$.

Por otra parte, los rituales más importantes para los jóvenes de la sociedad rural eran los festejos de los quintos, como el levantamiento del "Mayo"41. Esta festividad

\footnotetext{
${ }^{35}$ AHPZ, Sentencias criminales, año 1912, no 78.

${ }^{36}$ Este tipo de violencia ha sido denominada por Gutmaro Gómez Bravo como «violencia vecinal»; GÓMEZ BRAVO, Gutmaro, Crimen y castigo. Cárceles, justicia y violencia en la España del siglo XIX, Madrid, Catarata, 2005, p. 20.

${ }^{37}$ Para conocer más sobre el papel del honor como origen de la violencia campesina véase PLOUX, François, "Violence in France's Past: An Anthropological Approach", en BODY-GENDROT, Sophie y SPIERENBURG, Pieter (eds.), Violence in Europe. Historical and Contemporary Perspectives, New York, Springer New York, 2008, pp. 72-74.

${ }^{38}$ DAVIS, John, Antropología de las sociedades mediterráneas, Barcelona, Anagrama, 1983, p. 84.

${ }^{39}$ ARChV, Sentencias criminales, año 1906 ( $2^{\circ}$ semestre), $n^{\circ} 472$.

40 AHPP, Sentencias criminales, año 1916, Certificaciones de Sentencias de Jurado, $\mathrm{n}^{\circ}$ 26; es interesante, además, ver el desarrollo del juicio con las declaraciones de los testigos a través de la prensa: El Día de Palencia, 14, 15, 16, 17 y 18 de noviembre de 1916.

${ }^{41}$ CARO BAROJA, Julio, La estación de amor. (Fiestas populares de mayo a San Juan), Madrid, Taurus, 1983, p. 29.
} 
consistía en que los quintos pinaran en la plaza del pueblo un chopo desramado, el cual engalanaban y sorteaban al final del mes homónimo con el objeto de obtener dinero para sus fiestas. Este árbol se erigía en símbolo de virilidad de los mozos nacidos en un mismo año y, por lo tanto, en fuente de conflictos cuando era dañado ${ }^{42}$ : un grupo de jóvenes de Villaherreros arrancaron y quemaron el ramaje que coronaba el Mayo, afrenta a la que respondió un quinto disparando a tres de sus rivales con una escopeta de perdigones ${ }^{43}$; y en Cisneros, los quintos de 1923 entablaron una reyerta con los mozos que habían causado destrozos en el Mayo, resultando una víctima mortal por disparo con arma corta de fuego ${ }^{44}$.

La ronda era otra de las expresiones más importantes y cotidianas de la sociabilidad juvenil en el mundo rural ${ }^{45}$. En ella grupos de mozos recorrían las calles de la población por la noche bebiendo y cantando o, como alude la documentación, "escandalizando" y "alborotando". La celebración de estos rituales era causa de continuos altercados donde se dirimía el control de la calle para realizar este privilegio de los mozos. En Becerril de Campos se cruzaron dos grupos de jóvenes mientras realizaban su ronda, encuentro en el que "los primeros dijeron a los segundos que dejaran de tocar", entablándose una disputa que terminó con un herido por disparo de arma corta de fuego ${ }^{46}$. Y en Castrogonzalo, tras haber tenido unas palabras en un baile, se encontraron dos grupos de jóvenes mientras estaban de ronda por las calles de la localidad, originándose al instante una riña con aparición de "palos, armas blancas y de fuego", resultando de la refriega una víctima mortal por serle seccionada "la aorta abdominal" 4 .

Por otra parte, la propia realización de las rondas incitaba al ejercicio de la violencia ya que a través de éstas los mozos se hacían dueños de la noche ejecutando gamberradas en beneficio de la celebración. Tal es el caso de los robos que tenían como objeto el aprovisionamiento de recursos para la realización de la fiesta ${ }^{48}$, como ocurrió con un grupo de mozos en Fuentes de Nava:

“... siguiendo una costumbre de antiguo establecido, no sólo en el pueblo de Fuentes de Nava sino en otros de la provincia, y por la que los mozos en la víspera de algunas fiestas, y especialmente en el alistamiento de quintas, tienen costumbre de hacer hogueras en la citada noche, cogieron un carro que Marcela García Estébanez tenía colocado en la vía pública en la villa de Fuentes de Nava y dirigiéndose con aquél a una viña sita en el referido término municipal, y pago de la Carrezorita, cargaron veinte arrobas de cepas muertas de las que había allí amontonadas [...], de la propiedad de

\footnotetext{
${ }^{42}$ Véase para la Inglaterra del siglo XVIII: THOMPSON, Edward P., Costumbres en común, Barcelona, Crítica, 1995, p. 94.

${ }^{43}$ AHPP, Sentencias criminales, año 1906, no 268.

${ }^{44}$ AHPP, Sentencias criminales, año 1923, nº 120.

${ }^{45}$ BORDERIES-GUEREÑA, Josette, "Niños y niñas en familia”, en BORRÁS LLOP, José María (dir.), Historia de la infancia en la España contemporánea, 1834-1936, Madrid, Ministerio de Trabajo y Asuntos Sociales/Fundación Germán Sánchez Ruipérez, 1996, p. 50.

46 AHPP, Sentencias criminales, año 1907, no 25.

${ }^{47}$ AHPZ, Sentencias criminales, año 1912, Certificaciones de Sentencias de jurado, no 10.

${ }^{48}$ FABRE, Daniel, "Forjar la juventud...” art. cit., pp. 86-89.
} 
Doña Francisca Matía, y se marcharon con ellas en dirección a la plaza pública de la villa con objeto de hacer una hoguera la citada noche..." ${ }^{49}$

Otro ejemplo similar es el caso de los jóvenes de Itero de la Vega que penetraron en un plantío de chopos de propiedad comunal con el propósito de apropiarse de follaje para realizar las enramadas ${ }^{50}$ :

“... cortaron en alguno de ellos ramas y cañas [...] y las colocaron en las casas del pueblo de Itero de la Vega enramando las mismas, como es costumbre de hacerlo las vísperas de San Juan y San Pedro en el pueblo de Itero de la Vega y en casi todos los pueblos de la provincia para festejar las referidas fiestas y otras que se celebran todos los años..." ${ }^{p 1}$

Esta apropiación de todo lo que estuviera en la calle durante la noche por parte de la juventud era una regla implícita en la sociedad rural tradicional ${ }^{52}$, y también tenía su expresión mediante acciones violentas contra el mobiliario público y privado. Así, estando los mozos Nemesio Demetrio y Jesús Fulgencio "de ronda con otros jóvenes de San Esteban del Molar por las calles del expresado pueblo", al llegar a la plazuela de la Iglesia "movieron violentamente uno de los postes que sostienen los cables de la luz eléctrica, con el propósito de causar algunos daños y recrearse viendo saltar las chispas que se producían en los contactos". La consecuencia de dicha trastada fue dejar sin electricidad a todo el pueblo ${ }^{53}$. Del mismo modo, en Cuenca de Campos, "varios quintos [...] se entretuvieron en romper cristales de las casas" durante la madrugada del 15 al 16 de febrero de $1913^{54}$; y en Villada, cinco jóvenes en "momentos de juerga" causaron "importantes daños en fincas particulares y se dedicaron a romper las bombillas del alumbrado eléctrico de las calles de la villa"s5. Estas acciones, que podían enfurecer a los afectados, eran admitidas por la mayoría de sus convecinos ya que "era preciso condescender admitiendo que "la juventud es la juventud", aun con su desorden, su violencia y sus excesos"s6.

Sin embargo, las autoridades locales no opinaban lo mismo y no son desconocidos los casos en que los mozos se enfrentaron a aquéllas cuando pretendían poner fin a las rondas o, simplemente, cuando interrumpían u obstaculizaban cualquier costumbre mocil ${ }^{57}$. Estas confrontaciones reflejan la importancia que adquiría en la juventud

\footnotetext{
${ }^{49}$ AHPP, Sentencias criminales, año 1906, n ${ }^{\circ} 51$.

${ }^{50}$ Más sobre las enramadas en CARO BAROJA, Julio, La estación de amor... op. cit., pp. 75-76.

${ }^{51}$ AHPP, Sentencias criminales, año 1904, no 95.

${ }^{52}$ FABRE, Daniel, "Familias. Lo privado contra la costumbre", en ARIĖS, Philippe y DUBY, Georges (dirs.), Historia de la vida privada. 6. La comunidad, el Estado y la familia en los siglos XVIXVIII, Madrid, Taurus, 1991, p. 163.

${ }_{53}$ AHPZ, Sentencias criminales, año 1914, no 42.

${ }^{54}$ Diario Regional, 21 de febrero de 1913.

${ }^{55}$ El Diario Palentino, 1 de junio de 1923.

${ }^{56}$ FABRE, Daniel, "Forjar la juventud..." art. cit., p. 82.

${ }^{57}$ Algunos ejemplos de enfrentamientos entre mozos y autoridades en: GIL ANDRÉS, Carlos, Echarse a la calle. Amotinados, huelguistas y revolucionarios (La Rioja, 1890-1936), Zaragoza, Prensas Universitarias de Zaragoza, 2000, pp. 29-30 y 334-335; LUCEA AYALA, Víctor M., Rebeldes
} 
campesina los privilegios que poseían y que les identificaban como mozos. Cuando dos guardias nocturnos de Medina de Rioseco ordenaron mantener silencio a unos jóvenes que estaban "alborotando y alterando con sus gritos la tranquilidad del vecindario" la noche del 25 de julio de 1907, uno de los mozos "lejos de respetar las órdenes de dichos guardias, acometió con un palo y dio con él un golpe al referido guardia Tomás Ruano"s8. Y en Carrión de los Condes los serenos requirieron a otros jóvenes que dejasen de cantar, ante lo cual uno de los aludidos respondió que "no le daba la gana y que les iba a cortar el cuello y los cojones a todos los serenos" y, cuando aquéllos intentaron detenerle, el joven les amenazó con un cuchillo diciéndoles: "si me echáis mano os atravieso" 59 .

Pero los jóvenes no sólo actuaban contra las autoridades locales cuyo poder podía estar menoscabado por la cotidianeidad que caracterizaban a las relaciones sociales existentes en una comunidad local de pequeña escala, sino que también se enfrentaban a autoridades foráneas, como la Guardia Civil. Una pareja de la Benemérita, que acudió a poner paz en un alboroto protagonizado por un grupo de jóvenes de Boadilla de Rioseco, fue acometida por éstos, teniendo que refugiarse en una casa contra la que se hicieron varios disparos ${ }^{60}$. Y en Villalón de Campos, durante la noche del 4 de septiembre de 1904, se produjo un alboroto en la calle de la Rúa "con motivo de una disputa suscitada entre varios mozos", en la que intervino el alcalde, "acompañado de varios números de la guardia civil". La reacción de los jóvenes fue rebelarse contra las citadas autoridades, sobre las que "se arrojaron piedras y dispararon varios tiros" 61.

E incluso tenemos algunos pocos ejemplos de cómo estas agresiones juveniles se podían extender hasta las autoridades eclesiásticas. Estando un grupo de jóvenes de ronda en Montealegre de Campos, "promoviendo escándalo, conturbando el sosiego público y atentando al decoro con blasfemias y hechos injuriosos para algunos vecinos del mismo", fueron exhortados por un sacerdote de la localidad para que "depusieran su incorrecta actitud". Lejos de amilanarse, los mozos se abalanzaron sobre el clérigo "golpeándole bárbaramente hasta hacerle dar con su cuerpo en tierra y produciéndole fuertes lesiones en el labio superior, la rotura de varios dientes y erosiones de alguna consideración en la región cervical"'62.

Para terminar con las manifestaciones de violencia colectiva juvenil de la sociedad rural hablaremos de las cencerradas. Estas acciones tenían como objetivo el señalar al individuo que transgredía el orden moral de la comunidad, principalmente aquellos viudos o viudas que se casaban en segundas nupcias con una pareja más joven ${ }^{63}$; aunque, como sucedía en el caso en algunos pueblos palentinos de la co-

y amotinados. Protesta popular y resistencia campesina en Zaragoza (1890-1905), Zaragoza, Prensas Universitarias de Zaragoza, 2005, pp. 244-246; BASCUÑÁN AÑOVER, Óscar, Protesta y supervivencia. Movilización y desorden en una sociedad rural: Castilla-La Mancha, Alzira (Valencia), Fundación Instituto de Historia Social, 2008, p. 155.

${ }^{58}$ ARChV, Sentencias criminales, año 1905 ( ${ }^{\circ}$ semestre), $\mathrm{n}^{\circ} 380$.

${ }^{59}$ AHPP, Sentencias criminales, año 1908, ${ }^{\circ} 42$.

${ }^{60}$ El Día de Palencia, 6 y 8 de febrero de 1905.

${ }^{61} \mathrm{ARChV}$, Sentencias criminales, año 1906 ( ( $^{\mathrm{er}}$ semestre), $\mathrm{n}^{\mathrm{o}} 152$.

${ }^{62}$ Diario Regional, 28 de enero de 1910 y El Norte de Castilla, 29 de enero de 1910.

${ }^{63}$ Sobre las cencerradas véase THOMPSON, Edward P., Costumbres en común... óp. cit., pp. 520- 
marca, las cencerradas también se podían realizar por otra serie de intransigencias ${ }^{64}$. Los encargados de denunciar estos excesos eran esencialmente los jóvenes, con el beneplácito de los adultos ${ }^{65}$, mediante la organización procesiones grotescas, como sucedía en Morales de Campos:

“... se reúnen hombres y mujeres provistos de latas, cencerros, esquilas, pucheros en donde ponen un poco de lumbre y atado con cuerdas como incensario queman materias mal olientes. A veces con una colcha y cuatro palos hacen una especie de palio y al salir de la iglesia obligan a los novios velis nolis a ponerse debajo y con un regimiento detrás les llevan con grande estrépito" ${ }^{96}$

En estas acciones no era extraño que la ridiculización pública enfureciera a la víctima, la cual terminaba por agredir a los partícipes en el escándalo, tal como ocurrió en Pedraza de Campos donde fueron apedreados varios individuos que "se entretenían en tocar cencerros y cantar coplas injuriosas" en la puerta de un vecino ${ }^{67}$; o, en el caso contrario, que los propios protagonistas de la cencerrada se revolvieran violentamente contra quiénes intentaran poner fin a su acto: el 24 de febrero de 1911 "comenzaron a tocar por las calles del pueblo de Guaza, varios vecinos del mismo, cencerros y cuernos con el propósito de dar cencerrada a un viudo que estaba para celebrar segundo matrimonio, como de costumbre se venía verificando en casos análogos", alboroto en el cual tuvo que intervenir el alcalde que terminó siendo agredido por los participantes ${ }^{68}$. En otras ocasiones era el propio novio el objeto ya no sólo de la ridiculización pública, sino también de las agresiones físicas. Durante la cencerrada que se celebró en Villardefrades la noche del 3 de abril de 1904, los concurrentes insultaron a los moradores de la casa del novio, e incluso lanzaron algunas piedras contra la fachada, lo que hizo que saliera el perjudicado "a suplicarles se retirasen", sin embargo, éste sólo obtuvo como respuesta "varios golpes de palo en la cabeza"

594; y para el caso español CARO BAROJA, Julio, "El charivari en España", Historia 16, 47 (1980), pp. 54-70.

64 "En Frechilla, Mazuecos y otros pueblos palentinos propinan cencerradas a toda boda de jóvenes o viejos, de solteros o viudos, entre San Antón y Carnaval. Es una época tabú para casarse", en CASAS GASPAR, Enrique, Costumbres españolas de nacimiento, noviazgo, casamiento y muerte, Madrid, Edit. Escelicer, 1947, p. 315.

${ }^{65}$ SCHINDLER, Norbert, "Los guardianes del desorden..." art. cit., p. 339.

${ }^{6}$ MERINO ARROYO, Carlos y HERRERO GÓMEZ, Guillermo, La vida cotidiana en Valladolid a principios del siglo XX (Encuesta del Ateneo 1901-1902), Valladolid, Ed. Castilla, 1999, p. 116.

${ }^{67}$ AHPP, Sentencias criminales, año 1917, $\mathrm{n}^{\circ} 82$.

${ }^{68}$ AHPP, Sentencias criminales, año 1911, $\mathrm{n}^{\circ} 65$.

${ }^{69} \mathrm{ARChV}$, Sentencias criminales, año 1905 ( $1^{\mathrm{er}}$ semestre), $\mathrm{n}^{\mathrm{o}} 44$. 


\section{Violencia interpersonal de los mozos: la defensa de la virilidad a través de la fuerza}

Como hemos visto, buena parte de la violencia que ejecutaron los mozos tuvo que ver con la defensa del honor colectivo, en ocasiones contra elementos foráneos y, principalmente, en el seno de la propia comunidad local. Sin embargo, la importancia del honor en las sociedades de pequeña escala en las que imperan las relaciones "cara a cara" se extiende a todos los aspectos de la vida y adquiere gran importancia en las relaciones interpersonales ${ }^{70}$. Nos referimos al "valer más" que señaló Julio Caro Baroja como alternativa de las clases populares al prestigio social que en la Edad Media encarnaba el caballero honorable, el cual sólo podía alcanzarse a través de la violencia ${ }^{71}$. De hecho, la defensa del honor a través de la acción violenta era una de las mejores formas de promoción social de las clases bajas dentro de la comunidad local ${ }^{72}$. Por otra parte, los mozos de la sociedad rural se regían por un código de hombría ${ }^{73}$. Este hecho, unido al concepto que imperaba en las sociedades rurales de la época donde se identificaba masculinidad con fuerza física, coraje y valentía ${ }^{74}$, originaba multitud de actos violentos, y en éstos muchas veces los protagonistas eran mozos, es decir, aquellos individuos que estaban más necesitados de manifestar socialmente su hombría.

De este modo, por ejemplo, no es raro ver cómo los jóvenes se erigían en defensores del honor familiar, sustituyendo al padre de familia ${ }^{75}$, a través de la defensa de sus miembros débiles e incluso del propio patriarca, como es el caso de Teodoro Prieto, mozo de Grijota que acometió con arma blanca a un convecino porque éste había herido previamente a su padre ${ }^{76}$. Una acción que no sólo se ejercía defendiendo físicamente a los familiares, sino también se buscaba preservar el buen nombre del grupo: el joven de 17 años Julián Mongín desafió a su convecino Pedro Hidalgo al oír que éste "hablaba mal de su familia [...] porque se oponía la misma a que sostuviera relaciones amorosas con una hermana del Julián", agrediéndose mutuamente con cacha y cuchillo ${ }^{77}$.

Aun con todo, lo común era que, a la hora de defender el honor familiar, los jóvenes hermanos o primos se unieran e hicieran causa común en las reyertas en las que se implicaba uno de ellos. En Urueña se produjo una reyerta en el baile celebrado el 6 de mayo de 1923 donde intervinieron de un lado Leovigildo, Artemio y Paulino

\footnotetext{
${ }^{70}$ PERISTIANY, John, “Introducción”, en PERISTIANY, John (ed.), El concepto del honor... óp. cit., pp. 13-14.

${ }^{71}$ CARO BAROJA, Julio, "Honor y vergüenza (Examen histórico de varios conflictos populares)", Revista de dialectología y tradiciones populares, 20 (1964), p. 418 y pp. 452-453.

${ }^{72}$ FARGE, Arlette, "Familias. El honor y el secreto", en ARIÈS, Philippe y DUBY, Georges (dirs.), Historia de la vida privada. 6... óp. cit., p. 203.

${ }^{73} \mathrm{O}$ por una "ética viril", tal como ha señalado SAAVEDRA, Pegerto, La vida cotidiana ... óp. cit., p. 204.

${ }^{74}$ VAQUINHAS, Irene, "Alguns aspectos da violencia..." art. cit., p. 300.

${ }^{75}$ La defensa del honor familiar ha sido definido como "regla elemental del espíritu familiar", en PERROT, Michelle, "Dramas y conflictos familiares", en ARIÈS, Philippe y DUBY, Georges (dirs.), Historia de la vida privada. 7. La Revolución francesa y el asentamiento de la sociedad burguesa, Madrid, Taurus, 1991, p. 269.

${ }^{76}$ AHPP, Sentencias criminales, año 1916, $\mathrm{n}^{\circ} 3$.

${ }^{77}$ AHPP, Sentencias criminales, año 1915, nº 49.
} 
Rodríguez de la Rosa, y de otro Gregorio y Joaquín Ortega Cebrián, todos los cuales rondaban la veintena, y en cuya riña resultaron dos heridos por los disparos de arma de fuego que realizaron Leovigildo y Gregorio ${ }^{78}$; y, del mismo modo, en Abastas sostuvieron una reyerta Francisco Garrido y Antonio Puebla, en la cual intervinieron sus respectivos hermanos, Luis Garrido y Mariano Puebla, este último esgrimiendo una navaja con la que hirió a sus rivales ${ }^{79}$.

En otro sentido, si hablamos de jóvenes y virilidad, una de las peores ofensas que podía sufrir un mozo era verse menoscabado en una relación amorosa, de modo que los "líos de faldas" también fueron origen de importantes y sangrientas reyertas. En Villafáfila, los mozos Quirino Fernández y Pablo García "disputaron por rivalidades amorosas" armados con sus respectivas armas blancas ${ }^{80}$. Y en Población de Campos se produjo un suceso con similar origen pero consecuencias más dramáticas. Al encontrarse los jóvenes Pedro Alonso y José Rojo en un camino del término municipal de la población, el primero mató de un disparo a su contrincante en una riña que tuvo su origen pocos días antes cuando:

\begin{abstract}
“... hallándose [Pedro Alonso] en las cercas de dicho pueblo conversando con una joven con quien sostenía relaciones amorosas, y a la que unos dos años antes había acompañado el José Rojo, se le acercó éste y dijo al procesado [Pedro] 'aquí estoy yo, tantas ganas como me tenías', contestándole 'sí te tengo ganas, pero hasta que no hagas motivos a ésta o a mí', diciéndole la joven al Pedro 'déjale', y repitiendo éste, 'cuando hagas a ésta o a mí motivos nos encontraremos', y entonces insultó a aquélla, sin que a pesar de ello el Pedro le dijera nada, pero al marcharse el José, dijo aquél a su novia 'el miércoles iremos al campo y si nos encontramos ya nos veremos'..."
\end{abstract}

Por otra parte, un buen escenario para que los mozos hicieran gala de su honorabilidad y valía era la taberna. Ésta era el principal espacio de ocio campesino ${ }^{82}$, lo cual, unido al consumo de alcohol y a la práctica de juegos de azar, desembocaba en no pocos actos violentos ${ }^{83}$. En este contexto, la constante presencia los miembros adultos masculinos de la comunidad local abocaba a los mozos a realizar continuas hombradas mostrando su virilidad. Por ejemplo, las partidas de cartas posibilitaban un frecuente cuestionamiento de la honorabilidad de los mozos en torno a las acusaciones de trampas y al pago de las apuestas realizadas, originando actos violentos como el ocurrido en una taberna de Villacid, donde se produjo una discusión entre cuatro jóvenes que jugaban al mus por "motivo del juego". Así las cosas, "en

\footnotetext{
${ }^{78}$ ARChV, Sentencias criminales, año 1924, no 52.

${ }^{79}$ AHPP, Sentencias criminales, año 1923, $\mathrm{n}^{\circ} 68$.

${ }^{80}$ AHPZ, Sentencias criminales, año 1909, nº 119.

${ }^{81}$ AHPP, Sentencias criminales, año 1918, Certificaciones de Sentencias de Jurado, $\mathrm{n}^{\circ} 2$. Más noticias sobre el homicidio en El Diario Palentino y El Día de Palencia, 2 de junio de 1907.

${ }^{82}$ URÍA GONZÁLEZ, Jorge, "La taberna en Asturias a principios del siglo XX. Notas para su estudio", Historia Contemporánea, 5 (1991), pp. 53-72; y "La taberna: un espacio multifuncional de sociabilidad popular en la Restauración española", Hispania, 214 (2003), pp. 571-604.

${ }^{83}$ BERNAL SERNA, Luis M., "Los espacios de la violencia. Tabernas y fiestas en Vizcaya (15601808)", Vasconia, 33 (2003), pp. 411-412.
} 
el revuelo y confusión que se produjo en aquellos momentos", uno de los tahúres recibió un golpe de jarro en la cabeza, a lo que respondió disparando el revólver que portaba en ese momento ${ }^{84}$. Otro suceso similar se produjo en otra taberna de Grijota donde cuestionaron tres mozos que junto a otros varios "se encontraban jugando a la brisca". Pasando de las palabras a los hechos, los contendientes se armaron de sus pistolas y:

“... al salir los dos procesados Estanislao y Benigno, entonces hicieron varios disparos en dirección a los otros que estaban en la taberna, con la hoja inferior de la puerta abierta, pues no dieron al amo Florentino a cerrarla del todo, y Matías e Indalecio desde dentro también dispararon sus pistolas contra Estanislao y Benigno" ${ }^{\text {85 }}$

El otro gran origen de los enfrentamientos violentos entre mozos en tabernas fueron las discusiones por el pago de rondas de bebida. Aquí también se ponía en cuestión la honorabilidad, ya que la capacidad de invitar una ronda de bebida no sólo mostraba generosidad hacia el otro, sino que también suponía una afirmación de preeminencia entre iguales y, por el contrario, el hecho de ser pagado sin corresponder a ello significaba que un hombre se colocaba en posición de inferioridad frente a su benefactor ${ }^{86}$. Dos jóvenes de Villalón de Campos "que habían estado tomando unas copas de vino en una taberna" acabaron discutiendo "por quien de ellos había de pagar el gasto" sacando sus navaja a relucir ${ }^{87}$. Otro ejemplo más sangriento es el protagonizado por dos jóvenes de Frómista, Andrés Relea y Pío Díez, quienes en una taberna tuvieron una cuestión "por la forma en que habían de satisfacer el importe del vino consumido", terminando por acometerse "mutuamente con armas blancas". Como resultado de la riña, Pío resultó con heridas que le provocaron la muerte a los pocos días ${ }^{88}$.

\section{Las armas: una cosa de "hombres"}

Numerosos autores han señalado la importancia y, sobre todo, la generalidad que tuvieron las armas en la sociedad española de finales del siglo XIX y principios del $\mathrm{XX}^{89}$, aspecto que también queda reflejado en nuestra comarca de estudio sólo con

${ }^{84}$ ARChV, Sentencias criminales, año 1912, no 45. Más noticias en El Norte de Castilla, 5 de octubre de 1911.

${ }^{85}$ AHPP, Sentencias criminales, año 1912, $\mathrm{n}^{\circ} 91$

${ }^{86}$ Más sobre la capacidad de pagar como una conducta honorable en PITT-RIVERS, Julian, "Honor y categoría... art. cit.”, pp. 58-59; sobre la importancia de las rondas de alcohol entre los jóvenes véase FABRE, Daniel, "Forjar la juventud..." art. cit., p. 79.

${ }^{87}$ ARChV, Sentencias criminales, año 1909 (1 ${ }^{\text {er }}$ semestre), no 28.

${ }^{88}$ AHPP, Sentencias criminales, año 1912, Certificaciones de Sentencia de Jurado, $\mathrm{n}^{\mathrm{o}} 25$. Los pormenores del consecuente juicio en El Diario Palentino, 17 y 18 de junio de 1912.

${ }^{89}$ BAUMEISTER, Martin, Campesinos sin tierra ... óp. cit., pp. 165 y 174; LAPESQUERA, Ramón, "Apuntes sobre la criminalidad en Navarra", Principe de Viana, 192 (1991), pp. 261-263; SIERRA ÁLVAREZ, José, "Rough characters. Mineros, alcohol y violencia en el Linares de finales del siglo XIX”, Historia Social, 19 (1994), p. 82; BASCUÑÁN AÑOVER, Óscar, "Delincuencia y desorden 
echar un vistazo a los numerosos ejemplos de enfrentamientos violentos señalados en este texto, o a la prensa de la época:
"No es la primera vez que en estas columnas nos hemos ocupado de los grandes es- tragos que produce la perniciosa costumbre de usar armas de fuego. [...]
La frecuencia con que se producen hechos como los que dieron lugar a la formación de las causas [judiciales] que últimamente se han visto en juicio oral, fruto son de la excesiva facilidad con que en poblado y en el campo se utilizan armas de todas clases y la inaprensión e imprudencia mostradas a toda hora y en todo lugar con tales instrumentos, por los que acostumbran a usarlas.
Parécenos llegado el momento de llamar una vez más la atención de las autoridades, y sobre todo de las de los pueblos sobre la más que imprudente tolerancia mostradas de algún tiempo a esta parte en el uso abusivo y tenencia por todo que dan de esos instrumentos deparadores frecuentes de la muerte" 90

Este hecho no sólo suponía la pervivencia de una costumbre de la vida cotidiana campesina que hundía sus raíces en el Antiguo Régimen, sino también una resistencia simbólica frente a la legislación del Estado de la Restauración que pretendía monopolizar y controlar el uso de las armas ${ }^{91}$.

Pero la importancia de las armas en la sociedad rural no tuvo una principal relación con actividades económicas propias del campesinado, como la caza, sino más bien con una mentalidad donde masculinidad y portar armas era algo indivisible ${ }^{92}$; y si había alguien que necesitaba más que nadie exteriorizar esa masculinidad, esos eran los mozos, de modo que éstos fueron quienes destacaron en el uso de armas.

Una buena manera de refrendar esta afirmación es acudir al tipo de causas judiciales a las que alude el artículo trascrito, o sea, las lesiones producidas por la imprudencia en la utilización de las armas de fuego.

social en la España agraria. La Mancha, 1900-1936”, Historia Social, 51 (2005), p. 135. En nuestro caso ya hemos hecho referencia a este hecho en REDONDO CARDEÑOSO, Jesús-Ángel, "Violencia y sociedad rural..." art. cit., pp. 99-102.

${ }^{90}$ El Diario Palentino, "Las armas de fuego", 25 de octubre de 1912.

91 Téngase en cuenta la amplia cantidad de leyes que se promulgaron entre 1875 y 1923 con objeto de limitar la presencia de armas de fuego en España pero que, sin embargo, y a tenor de los acontecimientos expuestos en el texto, tuvieron poco éxito: el Real Decreto del 23 de junio de 1876; el Real Decreto del 13 de agosto de 1876; la Circular del 20 de agosto de 1876; la Ley de Caza del 13 de enero de 1879; la Real Orden Circular del 21 de septiembre de 1894; la Ley de Caza del 18 de mayo de 1902; la Real Orden del 14 de septiembre de 1906; la Real Orden de 28 de septiembre de 1907; la Real Orden del 9 de noviembre de 1907; la Real Orden Circular del 18 de diciembre de 1907; la Circular de la Dirección General de Seguridad del 22 de febrero de 1914; la Real Orden del 30 de diciembre de 1915; la Ley de 29 de abril de 1920; el Real Decreto de 15 de septiembre de 1920; la Real Orden de 8 de noviembre de 1920; y Ley de 2 de Agosto de 1923.

${ }^{92}$ En este sentido E. P. Thompson ya advirtió cómo mientras los hombres hacían uso de garrotes y armas de fuego, las mujeres utilizaban en los enfrentamientos proyectiles como piedras o patatas, en THOMPSON, Edward P., Costumbres en común... op. cit., p. 373. La relación entre masculinidad y la utilización de armas también se ha visto en otro contexto bien distinto al aquí estudiado, como fue la Barcelona del pistolerismo; GONZÁLEZ CALLEJA, Eduardo, El máuser y el sufragio. Orden público, subversión y violencia política en la crisis de la Restauración (1917-1931), Madrid, CSIC, p. 233. 
A través de estas causas, que aunque particulares no fueron escasas, vemos cómo los jóvenes terracampinos presumían de sus pistolas y revólveres ante sus convecinos. Manuel Fernández, de 16 años y vecino de Ceinos de Campos, compró una pistola que se disparó "en ocasión de hallarse éste enseñando el arma a su amigo Domicio Torres" ${ }^{93}$. Más trágico fue el suceso protagonizado por Florencio Alonso, joven de 17 años, cuando "al enseñar [...] en la plaza mayor de Villada a varios jóvenes una pistola Browings" ésta se le disparó, produciendo a un compañero una herida mortal de necesidad ${ }^{94}$. Otro ejemplo más esclarecedor fue el suceso ocurrido en Villanueva del Rebollar donde vemos perfectamente la cotidianeidad con que eran tratadas las armas de fuego, las cuales, incluso, eran reparadas por los artesanos locales:

“...estando en su fragua el [herrero] Rudesindo, entró en ella el Fortunato [de 22 años], y diciendo éste a aquél 'te voy a enseñar una cosa buena' sacó un revólver que le entregó para que le viera sin hacerle advertencia alguna de que estuviera cargado, ni de su mecanismo tanto porque se veían las cápsulas, como por su pericia en el conocimiento de armas de fuego, puesto que las arreglaba, en cuyo momento entraron Pantaleón Pastor Melero y Vicente Laso Santiago, y cogiendo el Pantaleón al Rudesindo dicha arma, que tenía en la mano, se puso a examinarla, devolviéndosela después, poniéndose éste entonces a mirarla de nuevo, a discutir sobres sus condiciones y a manipular con ella de frente de los mismos, en cuyo acto se disparó, yendo el proyectil a herir al Vicente en la región abdominal..."95

Pero las armas de fuego no sólo eran actores pasivos en la sociabilidad informal juvenil. En la documentación manejada no es extraño encontrar ejemplos de cómo los mozos utilizaban las armas en sus juegos y bromas. Estando reunidos tres amigos en una casa de Villacidaler la mañana del 9 de noviembre de 1913, uno dijo a otro: "siéntate ahí, en la trébede que te voy a dar dos píldoras". Sacando a continuación "una pistola de dos cañones que hacía poco había encontrado", disparó sin saber si el arma estaba cargada o no. Simplemente ocurrió lo primero ${ }^{96}$. Otro ejemplo muy ilustrativo de estos peligrosos divertimentos ocurrió en una bodega de Támara de Campos donde estuvieron merendando varios amigos el 31 de marzo de 1911. Uno de los reunidos fue acusado por la Audiencia Provincial de Palencia por:

“... haber disparado, sin malicia y sin intención de causar daño alguno, dos tiros de pistola, uno de los cuales hirió de muerte a Manuel Chico, haciendo dichos disparos al tiempo que a intervalos se abría y cerraba la puerta del descargadero de la bodega en que poco antes habían merendado amigablemente con otros jóvenes, y en cuya bodega les había dejado encerrados por pura broma el Manuel y Pedro de la Fuente, los cuales y siguiendo la broma, les tiraban desde fuera piedras cuando por dicho descargadero intentaban salir..." ${ }^{97}$

\footnotetext{
${ }^{93} \mathrm{ARChV}$, Sentencias criminales, año 1901 ( $1^{\mathrm{er}}$ semestre), $\mathrm{n}^{\mathrm{o}} 126$.

${ }^{94}$ AHPP, Sentencias criminales, año 1918, Certificaciones de Sentencias de Jurado, no 15.

${ }^{95}$ AHPP, Sentencias criminales, año 1907, ${ }^{\circ} 41$.

${ }^{96}$ AHPP, Sentencias criminales, año 1914, $\mathrm{n}^{\circ} 109$.

${ }^{97}$ AHPP, Sentencias criminales, año 1912, Certificaciones de Sentencias de Jurado, $\mathrm{n}^{\circ}$ 31; detalles sobre el juicio en El Diario Palentino, 22 y 23 de octubre de 1912.
} 
E incluso las armas aparecen en escenas familiares de la vida privada. Daniel Merino, joven del pequeño pueblo de Población de Arroyo, que durante la tarde-noche del 1 de noviembre de 1906 "había estado merendando y cenando con otros mozos", llegó a casa altas horas de la noche, por lo que, para no molestar, se quedó a dormir en la cuadra. A primera hora de la mañana siguiente su madre ordenó a su hermano pequeño que le despertara "para que se levantase y fuera a trabajar". La reacción de Daniel, "sin duda molestado o indignado porque había ido a despertarle y no dejarle dormir", fue coger "el revólver que tenía sin licencia para usarle" y disparar a su hermano ${ }^{98}$.

Otros ejemplos que muestran la cotidianeidad con que los campesinos usaban las armas de fuego se producían en las fiestas. El disparo de salvas con armas de fuego era sinónimo de alegría y regocijo, por lo que su presencia y uso se multiplica en las escenas más cotidianas. En Villanueva del Campo, en los encierros corridos durante las fiestas de 1902, "Al llegar a las puertas de la plaza del ganado, varios zánganos hicieron algunos disparos", por lo que las reses se espantaron provocando más de un susto ${ }^{99}$; en Villada fueron detenidos seis jóvenes por celebrar la Nochevieja de 1906 "disparando armas de fuego en la vía pública" 100 ; y en Villavicencio de los Caballeros varios vecinos se quejaron que los jóvenes que rondaron durante la noche durante los últimos días del mes de marzo de 1911 "no sólo rompieron cristales proporcionando sustos, sino que hicieron varios disparos" ${ }^{\prime 101}$.

Esta utilización de las armas de fuego también está presente en el acto de sociabilidad formal probablemente más importante de las sociedades campesinas tradicionales, es decir, las procesiones. En ellas los jóvenes tenían la costumbre de custodiar a las imágenes sacras disparando al aire sus pistolas y revólveres ${ }^{102}$. En Villada, al "pasar la procesión por la calle de Sahagún [...] unos jóvenes que estaban haciendo salvas ocultos en un corral" dispararon una bala que rebotó en una pared, dando en el brazo de uno de los asistentes, no hiriéndole porque el proyectil ya estaba frío ${ }^{103}$; y en Revilla de Campos, el joven de 16 años Miguel Merino sacó "una pistola para hacer salvas, con motivo de celebrarse una procesión", arma que se disparó hiriendo a un compañero ${ }^{104}$. Del mismo modo, en Cisneros fue denunciado "un sujeto por disparo de arma de fuego al aire en el momento de pasar la procesión del Corpus" ${ }^{105} ; \mathrm{y}$, años más tarde, varios jóvenes del mismo pueblo acompañaron a la misma procesión "haciendo gran número de disparos por las calles del tránsito"106.

${ }^{98}$ AHPP, Sentencias criminales, año 1907, $\mathrm{n}^{\circ} 47$.

${ }^{99}$ Heraldo de Zamora, 18 de septiembre de 1902.

${ }^{100}$ El Día de Palencia, 3 de enero de 1907.

${ }^{101}$ Diario Regional, 1 de abril de 1911.

102 José Sánchez Jiménez ya señaló cómo la procesión del domingo de Resurrección en Tolox (Málaga) se realizaba "en medio de repique de campanas y de un largo disparo de cohetes y de tiros al aire"; en SÁNCHEZ JIMÉNEZ, José, Vida rural y mundo contemporáneo: análisis sociohistórico de un pueblo del sur, Barcelona, Planeta, 1973, pp. 43-44.

${ }^{103}$ El Diario Palentino, 3 de junio de 1904.

104 AHPP, Sentencias criminales, año 1907, no 88.

${ }^{105}$ El Día de Palencia, 14 de junio de 1909.

${ }^{106}$ El Diario Palentino, 29 de mayo de 1921. 


\section{Conclusión}

Si en textos pasados ya señalamos cómo la violencia interpersonal estaba muy generalizada en las comunidades rurales terracampinas de principios del siglo XX y que ésta constituía un "medio de defensa de su honor, prestigio social y respetabilidad dentro de la propia comunidad local" 107 - lo cual también se puede percibir en estudios acerca de otras regiones españolas como Castilla-La Mancha-108; en este trabajo hemos querido incidir en la importancia de la juventud como ejecutores de buena parte de ese corpus violento. En este sentido las estadísticas judiciales son muy tajantes: los jóvenes de entre 16 y 25 años eran los culpables de más de la mitad de los actos violentos ocurridos en las comunidades estudiadas y sentenciados por los juzgados provinciales.

Pero más allá de la importancia cuantitativa que tenía la violencia juvenil en las comunidades rurales estudiadas, nos ha parecido más interesante acercarnos a las causas que generaron dichas violencias. Los mozos entablaban buena parte de sus relaciones sociales a través de un amplio repertorio de actos violentos colectivos y de un mayor número de acciones individuales, pero estos sucesos tuvieron poco que ver con motivaciones políticas o conflictos socio-económicos de clase, aspectos que a menudo han sido sobrevalorados por la historiografía dedicada al estudio de la violencia ${ }^{109}$. Todo lo contrario, los jóvenes de las sociedades tradicionales habitualmente constituyeron "un frente único" dentro de la comunidad local"10.

Las reyertas entre bandos de mozos, la violencia en las rondas nocturnas, las riñas en defensa de la familia o las peleas de taberna tenían unas causas que, a nuestros ojos, pueden parecer algo banales, pero que suponían en centro neurálgico de las relaciones sociales cotidianas de los jóvenes campesinos. En un mundo donde buena parte estas relaciones se regían por facultades como el honor, el prestigio social y la respetabilidad de los vecinos, los jóvenes eran los individuos más necesitados de defender esas virtudes masculinas, porque ellos eran quienes debían de demostrar ante el conjunto de sus convecinos adultos que en un futuro cercano iban ser miembros dignos de la comunidad. En consecuencia, en unas mentalidades donde se identificaba masculinidad con fuerza física y valentía ${ }^{111}$, la defensa del honor pasaba casi irremediablemente por el ejercicio de la violencia.

De este modo los jóvenes campesinos de la Tierra de Campos de inicios del siglo XX se erigieron en los guardianes no sólo de unas costumbres que materializaban en

107 REDONDO CARDEÑOSO, Jesús-Ángel, "Violencia y sociedad rural..." art. cit., p. 103; también en Protesta y violencia de los campesinos castellano-leoneses: la Tierra de Campos (19001923), Palencia, Diputación de Palencia/Diputación de Valladolid, 2011 (en prensa).

${ }_{108}$ GÓMEZ BRAVO, Gutmaro, La violencia en Castilla-La Mancha durante la Restauración. 1875-1923, Toledo, Ediciones Parlamentarias de Castilla-La Mancha, 2006.

${ }^{109}$ La misma queja ya ha sido recogida por GÓMEZ BRAVO, Gutmaro, "Las violencia y sus dinámicas. Crimen y castigo en el siglo XIX español”, Historia Social, 51 (2005), pp. 93-110.

${ }^{110}$ FABRE, Daniel, "Forjar la juventud..." art. cit., p. 94. Sólo los jóvenes de clases extremas, es decir los pertenecientes a las elites y los pertenecientes a grupos marginados (mendigos, gitanos), se mantuvieron al margen de esta sociabilidad mocil.

${ }^{111}$ VAQUINHAS, Irene, “Alguns aspectos da violencia...” art. cit., p. 300. 
determinados ritos juveniles propios de las pequeñas comunidades rurales (cencerradas, enramadas, mayos, capeas, disparos de salvas en procesiones...), sino también de un código moral con claras raíces antiguorregimentales el cual amparaba la violencia si ésta se ejercía dentro de unos determinados límites ${ }^{112}$. La expresión más palpable de la continuidad de esta violencia reglada en la sociedad terracampina de aquellos años es la pervivencia de las armas de fuego entre el utillaje material de los jóvenes campesinos a pesar de la importante cruzada legislativa de los gobiernos de la Restauración para intentar erradicar esta costumbre popular española. En este sentido, si hablamos de los habitantes de la Tierra de Campos durante los primeros años del siglo pasado, debemos de asumir que "los jóvenes no son siempre, en todos los contextos históricos, protagonistas de la racionalidad o el cambio" ${ }^{113}$.

\footnotetext{
112 Véase a este respecto HOBSBAWM, Eric J., "Las reglas de la violencia", en Gente poco corriente. Resistencia, rebelión y jazz, Barcelona, Crítica, 1999, pp. 193-198.

${ }^{113}$ THOMPSON, Edward P., Costumbres en común... op. cit., p. 587.
} 